\title{
PPi plays a role in sugar starvation tolerance
}

\author{
Seedahmed A. Mohammed \\ Department of Biology and Biotechnology, Faculty of Science and Technology, AlNeelain University, Khartoum, Sudan, \\ seedahmed@neelain.edu.sd
}

\begin{abstract}
$\mathrm{H}^{+}$-PPase acidifies the endo-membrane compartments utilizing the energy of PPi hydrolysis. This acidification creates an electrochemical proton gradient that powers the secondary active transport and allows for vacuolar accumulation of several materials against their concentration gradients. The hydrolysis of the cytosolic PPi is necessary for the forwardness of the PPi-generating reactions. However, information is lacking on the role of PPi in adaptation to sugar starvation and low energy status in plants. Here, several mutants lacking the functional $\mathrm{H}^{+}$-PPases were used to illuminate this role. Three alleles of fugu5 mutants defective in type $\mathrm{I} \mathrm{H}^{+}$-PPase exhibited better tolerance to sugar starvation than wild-type plants, when grown on $1 / 2$ and full-strength MS media under photosynthesisconstraining low light intensity. The PPi level in fugu5 mutants was significantly higher than its level in wild type and type II $\mathrm{H}^{+}$-PPase-defective mutants. SnRK1 (Sucrose-non-fermenting1-Related kinase-1) plays a central role in the coordination of the plant transcriptome to the energy signals. SnRK1 senses the energy depletion in plant cells, and controls the expression of genes and phosphorylation of proteins in a way that promotes catabolism, and inhibits anabolism. Sugar starvation significantly induced the SnRK1 phosphorylation activity in wild type and type II $\mathrm{H}^{+}$-PPase lacking mutants. Whereas the activity remained unchanged in sugar-starved fugu5 mutants. This is possibly achieved through activation of PPi-dependent enzymes. Results suggest that the high PPi level in fugu 5 mutants might contribute to more efficiently use of low level of ATP under sugar starvation and low light conditions.
\end{abstract}




\section{Introduction}

The proton-pumping inorganic pyrophosphatases $\left(\mathrm{H}^{+}\right.$-PPases $)$acidify the endomembrane compartments using the energy stored in the phosphoanhydride bond of pyrophosphate to drive protons across endomembranes (Maeshima, 2001; Gaxiola et al., 2007). Two types of $\mathrm{H}^{+}$-PPases exist in plant cell. They differ in primary structures, ions sensitivity and localization. Type $\mathrm{I} \mathrm{H}^{+}$-PPase that localizes to the tonoplast is dependent on $\mathrm{K}^{+}$for its activities and moderately sensitive to the inhibition by $\mathrm{Ca}^{2+}$, whereas, type II $\mathrm{H}^{+}$-PPase that localizes to golgi and trans-golgi networks is $\mathrm{K}^{+}$insensitive but extremely $\mathrm{Ca}^{2+}$ sensitive (Drozdowicz et al., 2000).

In Arabidopsis genome there is a single type $\mathrm{I} \mathrm{H}^{+}$-PPase-encoding gene, namely, AtVHP1; 1, FUGU5, or AVP1; and two type II $\mathrm{H}^{+}$-PPase-encoding genes, namely, AtVHP2;1, or AVP2;1, and AtVHP2;2, or AVP2;2 (Drozdowicz \& Rea, 2001; Segami et al., 2010). The cellular content of type II $\mathrm{H}^{+}$-PPase is very low compared to that of type $\mathrm{I} \mathrm{H}^{+}$-PPase. Type II $\mathrm{H}^{+}$-PPases represent approximately 0.1 and $0.2 \%$ of the total $\mathrm{H}+$-PPases in microsomal fractions of suspension cells and young roots, respectively (Segami et al., 2010). Beside that, the PPi hydrolysis activity wasn't detected in fugu5 mutants, indicating that the contribution of type II $\mathrm{H}^{+}$-PPase in cytosolic PPi hydrolysis is fairly insignificant (Ferjani et al., 2011).

The expression patterns and/or the protein accumulation of the type $\mathrm{I} \mathrm{H}^{+}$-PPase suggested that it may play a role in accumulation of sugars and organic acids in vacuoles of peach (Etienne et al., 2002), pear (Suzuki et al., 1999) and grape (Venter et al., 2006). Type $\mathrm{I} \mathrm{H}^{+}$-PPase was also suggested to play a role at early stages of fruit development at the cell division stage (Mohammed et al., 2012). The roles of Type $\mathrm{I} \mathrm{H}^{+}$-PPase in growth and development are mediated by auxin transport (Li et al., 2005), or through the removal of excess levels of PPi to guarantee the forwardness of the sucrose-synthesis gluconeogenesis pathways (Ferjani et al., 2011). In contrast, information on the physiological roles of type $\mathrm{II} \mathrm{H}^{+}$-PPases in plant growth and development is lacking.

Inorganic pyrophosphate (PPi) is a by-product of several biosynthetic pathways (e.g. Nucleic acids, proteins, lipids, and polysaccharide polymerization) (Stitt, 1998; Heinonen, 2001). PPi generating and consuming reactions appear to be close to equilibrium, thus it needs to be hydrolyzed to ensure the forwardness of the polymerization and PPi-producing reactions (Weiner, 1987).

There are at least three PPi-utilization enzymes in the cytosol of plant cell. (I) UGPase (UDP-glucose pyrophosphorylase) catalyzes the formation of Glucose-1-phosphate and UTP from UDPGlc and PPi during sucrose degradation by sucrose synthase (Weiner, 1987; Stitt, 1998). (II) PFP (Pyrophsophatefructose 6-phosphate 1-phosphotransferase) which activates the phosphorylation of Fru6P using PPi as a phosphoryl donor (Weiner, 1987; Stitt, 1998). (III) The tonoplast-bounding proton pumping pyrophosphatase $\left(\mathrm{H}^{+}\right.$-PPase) that energizes the secondary active transport utilizing the PPi as energy source (Weiner, 1987; Stitt, 1998).

PPi can serve as an alternative energy source during ATP deficiency (Stitt, 1998). In contrast to the strong decline in ATP level under hypoxic conditions, PPi level was found to be relatively invariable (Mustroph, 2005; Dancer, 1989; Geigenberger, 2000; Mustroph et al., 2005). 
Tobacco and Potato plants with low PPi content due to the overexpression of E. coli inorganic pyrophosphatase, exhibited a strong defect in carbohydrate metabolism (Jelitto, 1992; Sonnewald, 1992). PPi removal affected the equilibrium between the reactants catalyzed by UGPase (Stitt, 1998).

UGPase plays different roles in source and sink tissues. In sink tissues, it works in sucrose breakdown, while in source tissues it facilitates sucrose biosynthesis (Kleczkowski, 1994; Coleman et al., 2007).

This study is aiming to shed light on the physiological roles of $\mathrm{H}^{+}$-PPases in sugar starvation tolerance. To Do this, fugu5, a type $\mathrm{I} \mathrm{H}^{+}$-PPase-loss of function mutant, and avp 2;1 and avp2;2 mutants were used. Results suggest a possible role for $\mathrm{H}^{+}$-PPases in energy deprivation response possibly through influencing the phosphorylation activity of SnRK1 (Sucrose non fermenting protein kinase I), the central coordinator of transcriptional networks of the stress and energy signaling.

\section{Materials and methods}

\section{Plant materials and growth conditions}

Arabidopsis thaliana ecotype Columbia (Col-0) or mutants in Col-0 background were used in this study. Seeds of fugu5 mutants, (fugu5-1, fugu5-2, and fugu5-3), were kindly provided by Dr. Ferjani (Ferjani et al., 2011). T-DNA insertion mutants avp2;1 (SALK_054291), and avp2;2 (SALK_138132C)) were obtained from The Arabidopsis Information Resource center (TAIR). Seeds were surface-sterilized by $500 \mu \mathrm{L}$ of a sterilization solution, consists of $5 \%(\mathrm{v} / \mathrm{v})$ sodium hypochlorite with $0.05 \%$ Tween 20 for 15 minutes. Seeds were then washed four times by sterilized distilled water. Plants were grown in half-strength MS medium only, or supplemented with $1 \%$ sucrose. All media were solidified by $0.7 \%$ agar and the $\mathrm{pH}$ was set to 5.7 . Seeds were stratified at $4{ }^{\circ} \mathrm{C}$ in the dark for 4 days, then they were incubated in growth chamber (NK system, Osaka, Japan) at $22^{\circ} \mathrm{C}$ under continuous light of $30 \sim 50 \mu \mathrm{mol} \mathrm{m}^{-2} \mathrm{~s}^{-1}$.

\section{Screening of $\mathrm{H}^{+}$-PPase-defective T-DNA insertion mutants}

Conventional PCR was performed to confirm the T-DNA insertion sites and to isolate homozygous lines. The left and right oligonucleotides for AVP2;1 (At1g78920) were GTGATTGGTATCGCCATCCT and ACAAACGAAGCACCAAAACC, respectively. For AVP2;2 (Atlg16780), the left primer was TGTCTTGCAGCCAGAAAGTG, and the reverse primer was TACCATTATGCCAGGCCTCT. The LBb1.3 T-DNA-specific primer was used in both cases.

\section{Expression analyses of $A V P_{-}$and $D I N$ genes}

Total RNA was extracted by using RNeasy Plant Mini Kit (Qiagen, Hilden, Germany), following the manufacturer's instructions. Genomic DNA contamination was eliminated by performing on-column digestion using RNase-free DNase I. RNA concentrations were measured by NanoDrop 1000 spectrophotometer (Thermo Fisher Scientific, Wilmington, USA). Complementary DNA (cDNA) was synthesized using Rever Tra Ace ${ }^{\circledR}$ qPCR RT Kit (Toyobo, Osaka, japan), following the manufacturer's instructions. Quantitative Real Time PCR was performed with MyiQ PCR machine 
(Bio-Rad, Hercules, CA, USA), using SsoAdvanced SYBR ${ }^{\circledR}$ green supermix (Bio-Rad, Hercules, CA, USA). Gene expression results were normalized against ACTIN2 gene expression.

List of primers used for $A V P s$ and DINs expression analysis

AVP1F1790 : 5'CTCCTTGGCTCTCTTTGGTG3'

AVP1R1940 : 5'AGCTGCACTTCCCACACTCT3'

AVP2;1F2287 : 5'ATCCCAGAAGTGTTCGTTGG3'

AVP2;1R2473 : 5'CTATGGCGACACAGCGACTA3'

AVP2;2F2279 : 5'TTGTCGCATCTTCAGCTTTG3'

AVP2;2R2487 : 5'CCAAGCACCTCCTGCTGTAT3'

AtAct2+494F : 5'TGCCAATCTACGAGGGTTTC3'

AtAct2+719R : 5'TTCTCGATGGAAGAGCTGGT3'

DIN1F467 : 5'CAGAGTCGGATCAGGAATGG 3'

DIN1R572 : : 5'ATTTGACCGCTCTCACAACC 3'

DIN6F1301 :5'ACTTGTCGCAAGATCAAG 3'

DIN6R1390 : :'GGAACACGTGCCTCTAGTCC 3'

\section{Extraction of total soluble proteins}

Total soluble proteins for SnRK1 assay were extracted following the method of Zhang et al. (2009) with a few modifications. In brief, about $200 \mathrm{mg}$ of seedlings grown in $1 / 2 \mathrm{MS}$ medium were finely ground in liquid nitrogen using a pestle and a mortar. Ground tissues were re-suspended in $600 \mu \mathrm{L}$ icecold homogenization buffer consists of $100 \mathrm{mM}$ Tricine- $\mathrm{NaOH}, \mathrm{pH} 8,25 \mathrm{mM} \mathrm{NaF}, 5 \mathrm{mM}$ dithiothreitol, $2 \mathrm{mM}$ tetrasodium pyrophosphate, $0.5 \mathrm{mM}$ EDTA, $0.5 \mathrm{mM}$ EGTA, $1 \mathrm{mM}$ bezamidine, 1 $\mathrm{mM}$ phenylmethylsulfonyl fluoride, Protease inhibitor cocktail (cOmplete; Roche Basel, Switzerland), Phosphatase inhibitors (PhosStop; Roche, Basel, Switzerland), and 2\% (w/v) polyvinylpyrrolidone. Homogenates were centrifuged at $13000 \mathrm{~g}$ for 15 minutes at $4{ }^{\circ} \mathrm{C}$. Supernatants were desalted with Illustra NAP-5 columns (GE Healthcare Life Sciences, Little Chalfont, UK) pre-equilibrated by homogenization buffer. Protease inhibitor cocktails and 2.5 $\mu \mathrm{M}$ Okadaic acid (Wako, Osaka, Japan) were added to the eluents before freezing in liquid nitrogen and storing at $-80^{\circ} \mathrm{C}$.

\section{SnRK1 activity assay}

SnRK1 assay was performed following previously described protocols (Davies et al., 1989; Weekes et al., 1993; Dale et al., 1995; Zhang et al., 2009) with a few modifications. SnRK1 assay medium consists of $40 \mathrm{mM}$ HEPES-NaOH, $\mathrm{pH} 7.5,5 \mathrm{mM} \mathrm{MgCl}$, $100 \mu \mathrm{M}$ ATP containing $12.5 \mathrm{kBq}\left(\gamma-{ }^{33} \mathrm{P}\right)$ ATP (PerkinElmer, Waltham, MA, USA), $200 \mu \mathrm{M}$ AMARA peptide (H-Ala-Met-ALa-Arg-Ala-AlaSer-Ala-Ala-Ala-Leu-ALa-Arg-Arg-Arg-OH (Enzo ${ }^{\circledR}$ Life Sciences, Farmingdale, USA)), 5 mM dithiothreitol, $1 \mu \mathrm{M}$ Okadaic acid, and protease inhibitor. Assay was started by adding $15 \mu \mathrm{L}$ of the reaction mixture to $10 \mu \mathrm{L}$ of the extracted total soluble protein. Incubated at $30^{\circ} \mathrm{C}$ for 6 minutes, $10 \mu \mathrm{L}$ of the extract-reaction mixture was added to $1 \mathrm{~cm}^{2}$ P81 Phosphocellulose paper squares (MERCK MILLIPORE, Billerica, MA, USA). The papers were immersed directly in $1 \%(\mathrm{w} / \mathrm{v})$ phosphoric acid (WAKO, Osaka, Japan). Then, they were washed four times in $1 \mathrm{~mL} 1 \%(\mathrm{w} / \mathrm{v})$ phosphoric acid, 
immersed in acetone for 15 minutes, air-dried and then added to $3 \mathrm{~mL}$ of scintillation cocktail (Ultima Gold ${ }^{\mathrm{TM}}$; PerkinElmer, Waltham, MA, USA). Incorporated $\mathrm{P}^{33}$ in AMARA peptide was quantified using a liquid scintillation counter (Beckman, CA, USA).

\section{Determination of PPi level}

PPi extraction was performed following the method of Kabala et al. (2010) with a few modifications. In brief, $200 \mathrm{mg}$ of seedlings were ground in liquid nitrogen before suspending in $1.5 \mathrm{~mL} 5.4 \%(\mathrm{v} / \mathrm{v})$ perchloric acid. The mixture was supplemented with $125 \mu \mathrm{L} 2 \mathrm{mM}$ Tris, and centrifuged at $7000 \mathrm{~g}$ for 5 minutes. The $\mathrm{pH}$ of the supernatants was set to 7.4 7.6 by adding few drops of $5 \mathrm{M} \mathrm{K}_{2} \mathrm{CO}_{3}$, and recentrifuged at $5000 \mathrm{~g}$ for 5 minutes. The clear supernatant was used for measuring PPi concentration by using PiPer Pyrophosphate Assay Kit (Life Technologies, Carlsbad, CA, USA).

\section{Results}

To understand the physiological function of $\mathrm{H}^{+}$-PPases in plant development, I used three lines of $A$. thaliana with defect in type $\mathrm{I} \mathrm{H}^{+}$-PPase, namely fugu5-1, fugu5-2, and fugu5-3 (Ferjani et al., 2011) and two homozygous T-DNA insertion lines, avp2;1 and avp2;2, were isolated from Salk collection using gene-specific and T-DNA specific primers (Fig. 1). The expressions of both AVP2;1 and AVP2;2 in avp2;1 and avp2;2 mutants were reduced significantly (Fig. 2)

\section{fugu5 mutants accumulate high level of PPi}

To determine the level of intracellular PPi, the soluble metabolites were extracted in $5.4 \%$ perchloric acid, and then the PPi concentration was measured through formation of the fluorescent resorufin by using PiPer Pyrophosphate assay kit. The results indicated that all fugu5 mutants accumulate significantly higher level of PPi than the wild-type plants (Fig. 1). The PPi levels in avp2;1 and avp2;2 mutants were significantly indifferent from that of wild-type plants (Fig. 3), suggesting that the role of type II $\mathrm{H}^{+}$-PPase in PPi hydrolysis could be minor.

\section{fugu 5 mutants showed higher tolerance to sugar starvation}

As a way of coping with energy deprivation, plants show a growth arrest and redirection of all cellular activity toward basic metabolism (Rolland et al., 2006). It is known that PPi can serve as an alternative energy source during ATP deficiency (Stitt, 1998). Because fugu5 mutants accumulate significantly higher level of inorganic pyrophosphate $\mathrm{PPi}$, resulting from to the loss of function of $\mathrm{H}^{+}-\mathrm{PPase}$, it was interesting to investigate the effect of energy deprivation on the growth of the mutants. The wild type, avp 2;1, avp 2;2, fugu5-1, fugu5-2, and fugu5-3 plants were grown on sugar-free half-strength MS medium and incubated at $22^{\circ} \mathrm{C}$ under low light intensity of $30 \sim 50 \mu \mathrm{mol} \mathrm{m} \mathrm{m}^{-2} \mathrm{~S}^{-1}$. Under these photosynthesis-constrained conditions, the wild-type plants exhibited growth and developmental arrest. This is mainly because of the low-light intensity, which wasn't enough to support the full autotrophic 
growth of seedlings when cultured on sugar-free medium. In contrast, the fugu5 outperformed the wild type and developed longer root systems (Fig. 4 and Fig. 5).

\section{The expression of the genes encoding $\mathrm{H}^{+}$-PPase is reduced under sugar starvation conditions}

Sugar regulates the expression of many genes directly or through interacting with many other signaling networks (Morkunas et al., 2012). To gain more insight into the role of $\mathrm{H}^{+}$-PPase in sugar starvation, I compared the expression level of $A V P 1, A V P 2 ; 1$, and $A V P 2 ; 2$ genes in wild-type seedlings subjected to sugar starvation, with their expression in $1 \%$ sucrose-containing $1 / 2$ MS medium. Results indicated a remarkable reduction in expression of all genes encoding $\mathrm{H}^{+}$-PPase. AVPl expression was reduced by $74 \%, A V P 2 ; 1$ by $79 \%$, and $A V P 2 ; 2$ by $76 \%$ (Fig. 6 ).

\section{DIN1 and DIN6 gene expression under sugar starvation conditions}

Dark-Inducible genes (DINs) are transcriptionally activated by energy depletion in darkness, sugar starvation and stress conditions (Baena-González et al., 2007). The tolerance response of fugu5 mutants to sugar starvation was higher than that of wild-type plants; therefore, I investigated the expression of DIN1 (At4g35770) and DIN6 (At3g47340) in $\mathrm{H}^{+}$-PPase-defective mutants. DIN1 encodes for a senescence- associated protein, and functions in RNA regulation. DIN6 encodes for a glutaminedependent asparagine synthetase and functions in amino acid metabolism. Both gene expressions are known to be induced in the dark and under sugar starvation. Results showed that, the level of DIN1 transcripts in avp 2; 1, avp 2;2, fugu5-1, fugu5-2, and fugu5-3, in sugar starvation medium under light condition were $34 \%, 64 \%, 45 \%, 53 \%$, and $48 \%$ lower than that of control plants, respectively (Fig. 7 A). The induction of DIN6 by sugar starvation was remarkably reduced in $\mathrm{H}^{+}$-PPase-defective mutants compared to wild-type plants (Fig. 7 B). These results indicate that under low-light conditions, the induction of DINS genes by sugar starvation in $\mathrm{H}^{+}-$PPase-defective mutants is lower than that of wildtype plants.

\section{SnRK1 activity is reduced in fugu 5 mutants}

To further understand the mechanisms that caused the better growth performance of $\mathrm{H}^{+}$-PPase mutants, I assayed the phosphorylation activity of SnRK1. SnRK1 is functionally and structurally related to the yeast sucrose-non-fermenting-1-kinase and animals AMP-activated protein kinase (Hey et al., 2007). SnRK1 senses the metabolic status and allow plants to adapt to stress conditions by promoting catabolism and inhibiting anabolism, and thus it saves ATP to be used for pivotal cellular processes (Tome et al., 2014). AMARA peptide, the specific substrate for SnRK1 (Dale et al., 1995; Salt et al., 1998) and radiolabeled ATP have often been used to investigate the SnRK1 activity. The SnRK1 phosphorylation activity in extracts of total soluble proteins of seedlings was induced significantly by sugar starvation in wild type, avp2;1 and avp2;2 mutants, but not in fugu5 mutants. The reduction of 
SnRK1 activity could be one of the reasons behind the better growth performance of fugu5 mutants under sugar starvation conditions (Fig. 8).

\section{Discussion}

Plants have a sessile nature. Therefore, they must continuously sense and coordinate their metabolism with internal and external signals to optimize growth and development (Tomé et al., 2014). Sugars, particularly sucrose and glucose, play crucial roles in this coordination. Sugars function not only as energy sources and structural components; they also work as central regulators for metabolism, physiology, development, and gene expression of many vital processes such as photosynthesis, respiration, cell cycle regulation, nitrogen metabolism, pathogen defense, wounding response, and senescence (Jang et al., 1997). Stress conditions such as nutrient scarcity, hypoxia, salts, and extreme temperatures; often affect photosynthesis and respiration in source leaves. Therefore, it can lead to growth arrest due to the massive alteration in cellular process (Tomé et al., 2014).

In this study, the wild-type plants exhibited growth arrest phenotype, when grown in sugar free basal medium under low light conditions. The low photosynthesis wasn't able to support the full autotrophic growth of wild-type plants. Xiong et al. (2013) showed a similar phenotype in Arabidopsis plants grown in sugar-free medium and low light intensity of $75 \mu \mathrm{mol} \mathrm{m} \mathrm{m}^{-1}$. In this study Arabidopsis plants were grown at even weaker light intensity of $30-50 \mu \mathrm{molm}^{-2} \mathrm{~s}^{-1}$. In general, plants react with sugar starvation and energy deprivation by arresting growth and redirecting cellular activities toward basic metabolism, by enhancing catabolism and inhibiting anabolism (Rolland et al., 2006).

Beside their roles as energy sources, sugars also regulate expression of hundreds of genes in plants (Kunz et al., 2014). It has been shown that the expression of 983 genes is upregulated, whereas the expression of 771 genes is downregulated in Arabidopsis in response to glucose at 3\% (Li et al., 2006). The expression of vacuolar pyrophosphatase genes is downregulated during sugar starvation. This suggest that the inhibition of these genes spares their substrate, PPi, to be used for coping with starvation conditions.

The fugu5-3 mutant accumulates 50\% more PPi than wild-type plants indicating that $A V P 1$ is the main hydrolyser of the cytosolic PPi (Ferjani et al., 2011). I found that beside fugu5-3, fugu5-2 and fugu5-1 accumulate significantly higher levels of PPi. PPi producing and utilizing reactions are reversal. The high PPi level could inhibit PPi-producing reactions (e.g. polymerization reactions), and thus it was expected to affect plant growth negatively. Contrary to the expectations, however, all fugu5 mutants displayed higher tolerance to sugar starvation and better performance in term of growth than wild-type plants.

Results propose that the phenotype of starvation tolerance could be attributed, at least in part, to the high amount of PPi accumulated in the cytosol of fugu5 mutants. High nitrogen level in growth medium enhances plant growth. Adequate sucrose concentration is necessary for this enhancement (George et al., 2007). This is possibly one of the main reasons of severe growth arrest in full strength compared to half strength MS medium under low light conditions (Data not shown). 
Energy depletion can affect the expression of many genes (Usadel et al., 2008). These genes form a network that regulates plant metabolism under stress conditions for optimum energy preservation (Avin-Wittenberg et al., 2012). The expression level of $\mathrm{H}^{+}$-PPase-encoding genes was reduced significantly (Fig. 5). It is possibly a way of energy conservation through increasing of PPi level, which can replace ATP for powering some reactions (Stitt, 1998).

DIN genes expression was reduced in $\mathrm{H}^{+}$-PPase-defective mutants comparing to wild-type plants. However, the expression was not correlated with the growth-retarded phenotype of fugu 5 mutants, as both type I and II $\mathrm{H}^{+}$-PPase-defective mutants showed a reduced expression for DINs. DIN genes work downstream of SnRK1. The phosphorylation activity of SnRK1 indicates the energy status of plants.

Interestingly, the transgenic Arabidopsis plants overexpressing OsSnRK1 showed hypersensitivity to high glucose concentrations, while the transgenic plants expressing inactive OsSnRK1 were insensitive (Cho et al., 2012). SnRK1 is a master regulator and central coordinator of plant transcription networks to stress and energy signaling (Baena-González et al., 2007). Transient elevation of SnRK1 results in activation of many genes involve positively in stress- and starvation-responses, or inhibition of expressions of many genes correlated with activation by sucrose, glucose, and elevated $\mathrm{CO}_{2}($ Sheen, 2014). I examined the SnRK1 activity in $\mathrm{H}^{+}$-PPase-defective mutants. The results showed that the activity was reduced significantly in fugu 5 mutants compared to wild-type and type II $\mathrm{H}^{+}$-PPase mutant plants under sugar-starvation conditions. This result suggests that the high PPi level in fugu 5 mutants is responsible, at least in part, for the reduced activity of SnRK1.

ATP available for different cellular process could mediate this reduction. PPi can serve as an alternative energy source during ATP deficiency (Stitt, 1998). In contrast to the strong decline in ATP level under hypoxic conditions, PPi level was found to be relatively invariable (Dancer \& Rees, 1989; Geigenberger et al., 2000; Mustroph et al., 2005). The high PPi level might help in conservation of ATP, probably through activation of PPi-dependent enzymes such as sucrose synthase, UGPase, and PEP rather than the ATP-depending enzymes. The conserved availability of ATP reduces the starvation, and this may explain the reduced SnRK1 activity. I propose a hypothetical model for the PPi-mediated sugar starvation tolerance (Fig. 9). Plants on MS medium rely partially on exogenous sugar till the photosynthetic apparatus becomes competent (Leon and Sheen, 2003). The low light intensity isn't enough to support the full autotrophic growth (Xiong et al., 2013). The low light and the absence of sugars from the growth medium induce energy depletion. The low ATP:AMP ratio due to the starvation activates SnRK1 by phosphorylation of the catalytic subunit of the complex (Mohannath et al., 2014). Phosphorylated SnRK1 will control the plant transcriptome by phosphorylation of several transcription factors controlling genes that promote catabolic reactions and inhibit anabolic reactions (Tome et al., 2014). The growth is arrested as a result of regulation by SnRK1. When sucrose is available in the nutrient medium, the high ATP:AMP ratio will reduce the SnRK1 activity. This in turn will ease the control over growth and anabolic reactions. The results suggest that the high PPi level in fugu5 mutants might contribute to conservation of ATP level. Sucrose degradation by invertase followed by phosphorylation of resulted hexoses by fructokinase and hexokinase requires two molecules of ATP. Whereas, sucrose degradation by sucrose synthase (SUSY) followed by phosphorylation of fructose by fructokinase requires only one molecuole of ATP with UGPase 
requiring one molecule of PPi. The formed UTP can be converted to ATP by nucleoside-5-diphosphate kinase and used to phosphorylate fructose (Dancer et al., 2005). Fructose-6-phosphate is phosphorylated by ATP-dependent phosphofructokinase (PFK) or PPi-dependent phosphofructokinase. Results suggest that the PPi-dependent pathways have the preference over the ATP-dependent pathways during sugar starvation under low light conditions in Arabidopsis.

\section{References}

Avin-Wittenberg, T., Tzin, V., Angelovici, R., Less, H., and Galili, G. (2012). Deciphering energyassociated gene networks operating in the response of Arabidopsis plants to stress and nutritional cues. Plant J. 70, 954-966. doi: 10.1111/j.1365-313X.2012.04926.x

Baena-González, E., Rolland, F., Thevelein, J. M., \& Sheen, J. (2007). A central integrator of transcription networks in plant stress and energy signalling. Nature, 448(7154). doi:10.1038/nature06069.

Cho, Y. H., Hong, J. W., Kim, E. C., \& Yoo, S. D. (2012) Regulatory functions of SnRK1 in stressresponsive gene expression and in plant growth and development. Plant Physiology, 158(4): 19551964. doi:10.1104/pp.111.189829.

Dale, S., Wilson, W. A., Edelman, A. M., \& Hardie, D. G. (1995). Similar substrate recognition motifs for mammalian AMP-activated protein kinase, higher plant HMG-CoA reductase kinase-A, yeast SNF1, and mammalian calmodulin-dependent protein kinase I. FEBS Letters, 361(2-3), 191-195.

Dancer et al., 2005

Dancer, J. E., Rees, T. (1989) Effects of 2,4-dinitrophenol and anoxia on the inorganic pyrophosphate content of the spadix of Arum maculatum and the root apices of Pisum sativum. Planta, 178: 421-424. doi: 10.1007/BF00391871.

Davies, S. P., Carling, D., \& Hardie, D. G. (1989). Tissue distribution of the AMP-activated protein kinase, and lack of activation by cyclic-AMP-dependent protein kinase, studied using a specific and sensitive peptide assay. European Journal of Biochemistry, 186(1-2), 123-128. doi:10.1111/j.14321033.1989.tb15185.x.

Drozdowicz, Y. M., Kissinger, J. C., \& Rea, P. A. (2000). AVP2, a sequence-divergent, K ${ }^{+}$ insensitive $\mathrm{H}^{+}$-translocating inorganic pyrophosphatase from Arabidopsis. Plant Physiology, 123(1), 353-362.

Etienne, C., Rothan, C., Moing, A., Plomion, C., Bodénès, C., Svanella-Dumas, L., Cosson, P., Pronier, V., Monet, R., Dirlewanger, E. (2002). Candidate genes and QTLs for sugar and organic acid content in peach [Prunus persica (L.) Batsch]. Theoretical and Applied Genetics, 105(1), 145-159. doi:10.1007/s00122-001-0841-9.

Ferjani, A., Segami, S., Horiguchi, G., Muto, Y., Maeshima, M., \& Tsukaya, H. (2011). Keep an Eye on PPi: The Vacuolar-Type $\mathrm{H}^{+}$-Pyrophosphatase Regulates Postgerminative Development in Arabidopsis. The Plant Cell Online, tpc.111.085415. doi:10.1105/tpc.111.085415.

Gaxiola, R. A., Palmgren, M. G., \& Schumacher, K. (2007). Plant proton pumps. FEBS Letters, 581(12), 2204-2214. doi:10.1016/j.febslet.2007.03.050. 
Geigenberger, P., Fernie, A. R., Gibon, Y., Christ, M., \& Stitt, M. (2000). Metabolic activity decreases as an adaptive response to low internal oxygen in growing potato tubers. Biological Chemistry, 381(8), 723-740. doi:10.1515/BC.2000.093.

George, E. F., Hall, M. A., \& Klerk, G.-J. de. (2007). Plant Propagation by Tissue Culture: Volume 1. The Background. Springer Science \& Business Media.

Heinonen, J. K. (2001) Biological Production of PPi. In Biological Role of Inorganic Pyrophosphate (pp. 1-28). Springer US. Retrieved from http://link.springer.com/chapter/10.1007/978-1-4615-1433$6 \_1$.

Hey, S., Mayerhofer, H., Halford, N. G., and Dickinson, J. R. (2007) DNA sequences from Arabidopsis, which encode protein kinases and function as upstream regulators of Snf1 in yeast. The Journal of Biological Chemistry, 282(14): 10472 - 10479. doi: 10.1074/jbc.M611244200.

Huang, S., Colmer, T. D., \& Millar, A. H. (2008) Does anoxia tolerance involve altering the energy currency towards PPi? Trends in Plant Science, 13(5): 221-227. doi:10.1016/j.tplants.2008.02.007.

Jang, J. C., León, P., Zhou, L., \& Sheen, J. (1997). Hexokinase as a sugar sensor in higher plants. The Plant Cell Online, 9(1), 5-19. doi:10.1105/tpc.9.1.5.

Jelitto, T., Sonnewald, U., Willmitzer, L., Hajirezaei, M., \& Stitt, M. (1992) Inorganic pyrophosphate content and metabolites in potato and tobacco plants expressing E. coli pyrophosphatase in their cytosol. Planta 188: 238- 244.

Kabała, K., Janicka-Russak, M., \& Kłobus, G. (2010). Different responses of tonoplast proton pumps in cucumber roots to cadmium and copper. Journal of Plant Physiology, 167(16), 1328-1335. doi:10.1016/j.jplph.2010.03.020.

Kunz, S., Pesquet, E., and Kleczkowski, L. A. (2014). Functional Dissection of Sugar Signals Affecting Gene Expression in Arabidopsis thaliana. PLOS ONE. 9(6): e100312. https://doi.org/10.1371/journal.pone.0100312.

Li Y, Lee KK, Walsh S, Smith C, Handingham S, Sorefan K, Cawley G, Bevan MW (2006) Estabilishing glucose- and ABA-regulated transcription networks in Arabidopsis by microarray analysis and promoter classification using a Relevance Vector Machine. Genome Res 16: 414-427.

León, P., \& Sheen, J. (2003) Sugar and hormone connections. Trends in Plant Science, 8(3), 110-116. doi:10.1016/S1360-1385(03)00011-6.

Maeshima, M. (2001). TONOPLAST TRANSPORTERS: Organization and Function. Annual Review of Plant Physiology and Plant Molecular Biology, 52, 469-497. doi:10.1146/annurev.arplant.52.1.469.

Mertens, E., Larondelle, Y., \& Hers, H. G. (1990). Induction of pyrophosphate:fructose 6-phosphate 1-phosphotransferase by anoxia in rice seedlings. Plant Physiology, 93(2), 584-587.

Mohammed, S. A., Nishio, S., Takahashi, H., Shiratake, K., Ikeda, H., Kanahama, K., \& Kanayama, Y. (2012). Role of Vacuolar $\mathrm{H}^{+}$-inorganic pyrophosphatase in tomato fruit development. Journal of Experimental Botany, 63(15), 5613-5621. doi:10.1093/jxb/ers213.

Mohannath, G., Jackel, J. N., Lee, Y. H., Buchmann, R.C., Wang, H., Patil, V., Adams, A. K., \& Bisaro, D. M. (2014) A Complex Containing SNF1-Related Kinase (SnRK1) and Adenosine Kinase in Arabidopsis. Plos One 9 (1) e87592.

Mustroph, A., Albrecht, G., Hajirezaei, M., Grimm, B., \& Biemelt, S. (2005). Low Levels of Pyrophosphate in Transgenic Potato Plants Expressing E. coli Pyrophosphatase Lead to Decreased Vitality Under Oxygen Deficiency. Annals of Botany, 96(4), 717-726. doi:10.1093/aob/mci223. 
Rolland, F., Baena-Gonzalez, E., \& Sheen, J. (2006). Sugar sensing and signaling in plants: conserved and novel mechanisms. Annual Review of Plant Biology, 57, 675-709. doi:10.1146/annurev.arplant.57.032905.105441.

Salt, I. P., Johnson, G., Ashcroft, S. J., \& Hardie, D. G. (1998) AMP-activated protein kinase is activated by low glucose in cell lines derived from pancreatic beta cells, and may regulate insulin release. Biochemical Journal, 33(3): 533 - 539.

Sheen, J. (2014). Master regulators in plant glucose signaling networks. Journal of Plant Biology, 57(2), 67-79. doi:10.1007/s12374-014-0902-7.

Sonnewald, U. (1992) Expression of E. coli inorganic pyrophosphatase in transgenic plants alters photoassimilate partitioning in leaves. Plant Journal, 2: 571-581. doi: 10.1046/j.1365-313X.1992.t0126-00999.x.

Stitt, M. (1998). Pyrophosphate as an Energy Donor in the Cytosol of Plant Cells: an Enigmatic Alternative to ATP. Botanica Acta, 111(3), 167-175. doi:10.1111/j.1438-8677.1998.tb00692.x.

Suzuki, Y., Maeshima, M., \& Yamaki, S. (1999). Molecular Cloning of Vacuolar $\mathrm{H}^{+}-$ pyrophosphatase and Its Expression during the Development of Pear Fruit. Plant and Cell Physiology, 40(8), 900-904.

Tomé, F., Nägele, T., Adamo, M., Garg, A., Marco-llorca, C., Nukarinen, E., Pedrotti, L., Peviani, A., Simeunovica, A., Tatkiewicz, A., Tomar, M., Gamm, M. (2014). The low energy signaling network. Plant Physiology, 5, 353. doi:10.3389/fpls.2014.00353.

Venter, M., Groenewald, J.-H., \& Botha, F. C. (2006). Sequence analysis and transcriptional profiling of two vacuolar $\mathrm{H}^{+}$-pyrophosphatase isoforms in Vitis vinifera. Journal of Plant Research, 119(5), 469-478. doi:10.1007/s10265-006-0009-4.

Usadel, B., Bläsing, O. E., Gibon, Y., Retzlaff, K., Höhne, M., Günther, M., et al. (2008). Global transcript levels respond to small changes of the carbon status during progressive exhaustion of carbohydrates in Arabidopsis rosettes. Plant Physiol. 146, 1834-1861. doi: 10.1104/pp.107.115592

Weiner, H., Stitt, M., \& Heldt, H. W. (1987) Subcellular compartmentation of pyrophosphate and alkaline pyrophosphatase in leaves. Biochimica et Biophysica Acta (BBA) - Bioenergetics, 893(1): 1321. doi: 10.1016/0005- 2728(87)90143-5.

Weekes, J., Ball, K. L., Caudwell, F. B., \& Hardie, D. G. (1993). Specificity determinants for the AMP-activated protein kinase and its plant homologue analysed using synthetic peptides. FEBS Letters, 334(3), 335-339.

Xiong, Y., McCormack, M., Li, L., Hall, Q., Xiang, C., \& Sheen, J. (2013). Glucose-TOR signalling reprograms the transcriptome and activates meristems. Nature, 496(7444), 181-186. doi:10.1038/nature12030.

Zhang, Y., Primavesi, L. F., Jhurreea, D., Andralojc, P. J., Mitchell, R. A. C., Powers, S. J., Schluepmann, H., Delatte, T., Wingler, A., \& Paul, M. J. (2009). Inhibition of SNF1-related protein kinase 1 activity and regulation of metabolic pathways by trehalose-6-phosphate. Plant Physiology, 149(4), 1860-1871. doi:10.1104/pp.108.133934. 


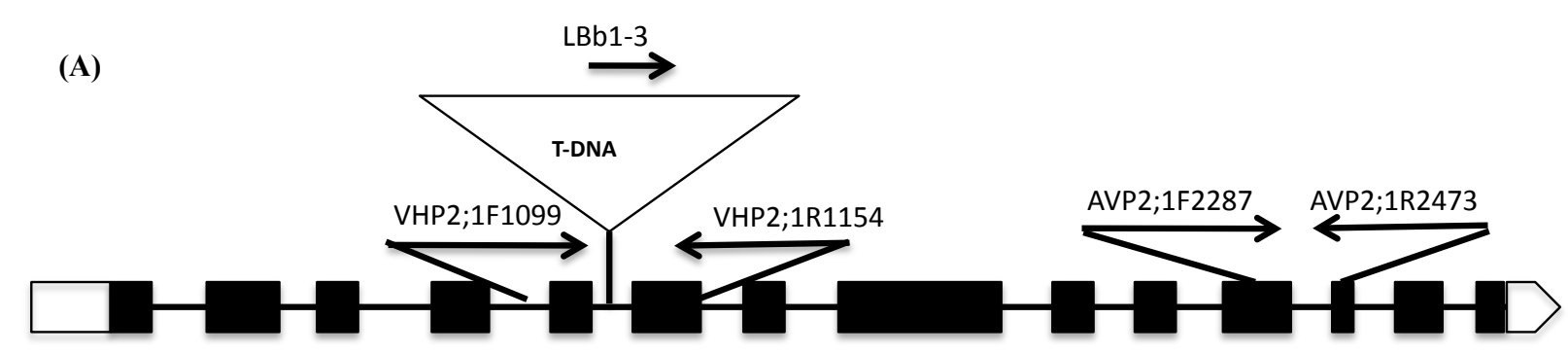

(B)

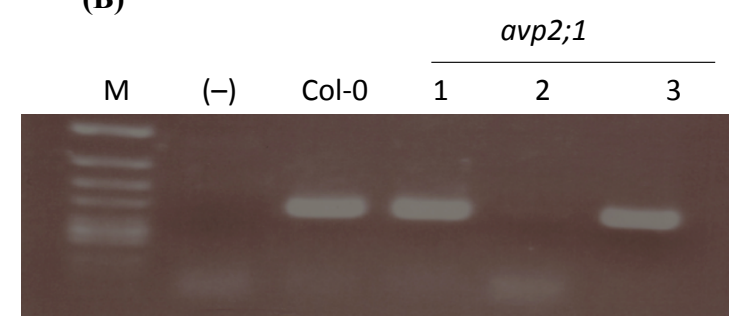

Gene specific primers

VHP2;1F1099 + VHP2;1R1544 (445 bp)

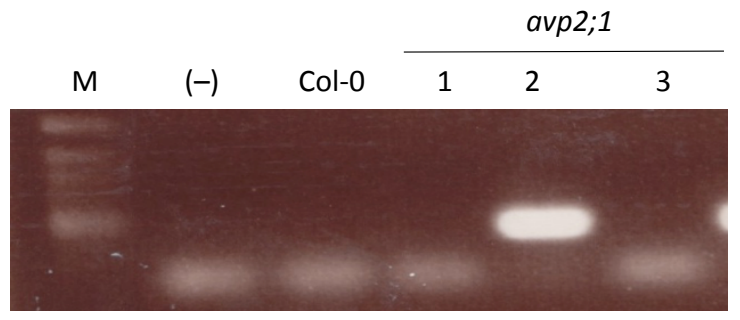

T-DNA specific primers

LBb1-3 + VHP2;1R1544 (386 bp) LBb1.3

(C)

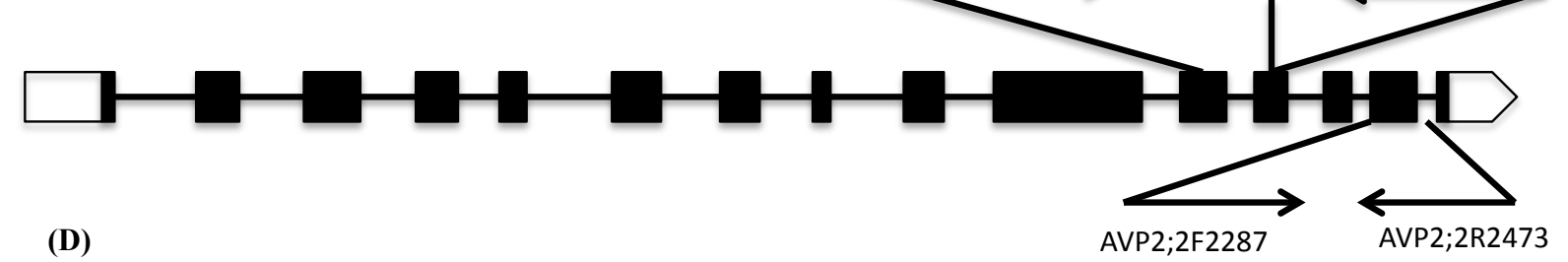

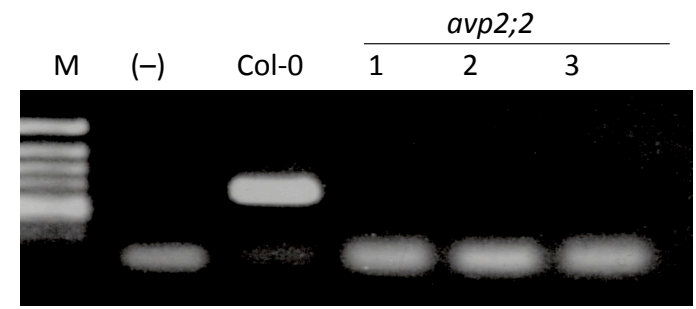

Gene specific primers VHP2;2F3204 + VHP2;2R3627 (424bp)

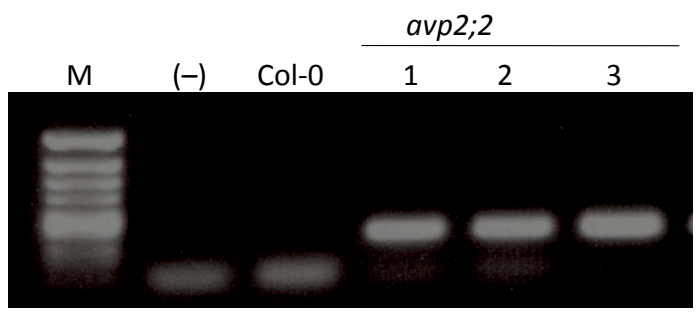

T-DNA specific primers VHP2;2F3204 + LBb1.3 (563 bp)

Fig. 1. Isolation of avp2;1 and avp2;2 mutants. Schematic diagrams show the position of T-DNA insertion in avp 2;1 (A) and avp 2;2 (C). Boxes indicate exons. Black boxes and white boxes indicate the translated and untranslated regions, respectively. Lines indicate introns. Small arrows represent primers, and the triangles indicate the T-DNA insertion.

(B) and (D) Agarose gel electrophoresis of the amplified PCR products of WT and T-DNA insertion mutants. M lane indicates the $\phi X 174$ Hinc II digest molecular marker, (-) is for negative control to which DNA template was not added. Col-0 is the wild type, and lane 1 to 3 are the examined plants of T-DNA insertion. lines No. 2 in (B), and No. 1 and 3 in (D) were homozygous mutations of T-DNA insertion. 
(A)

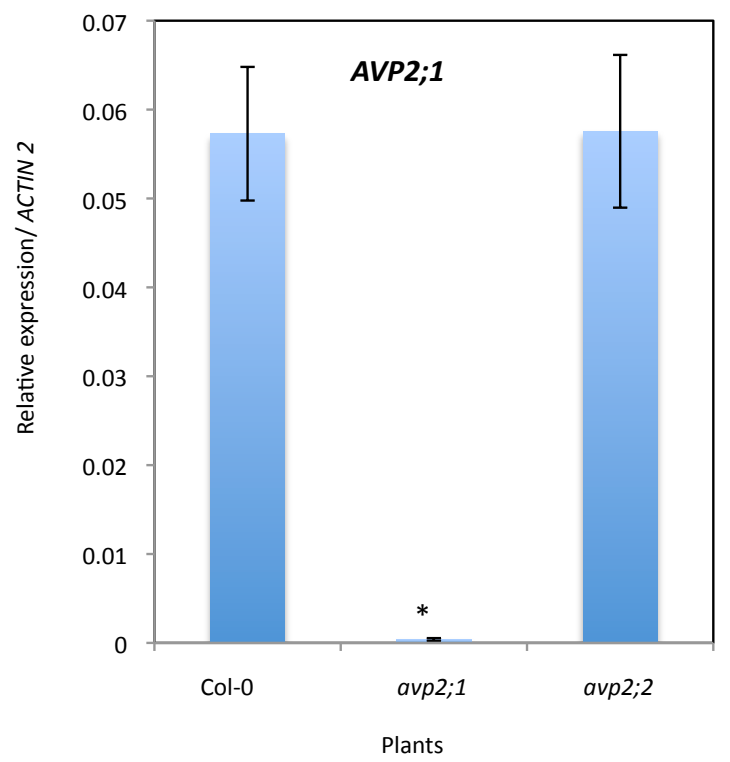

(B)

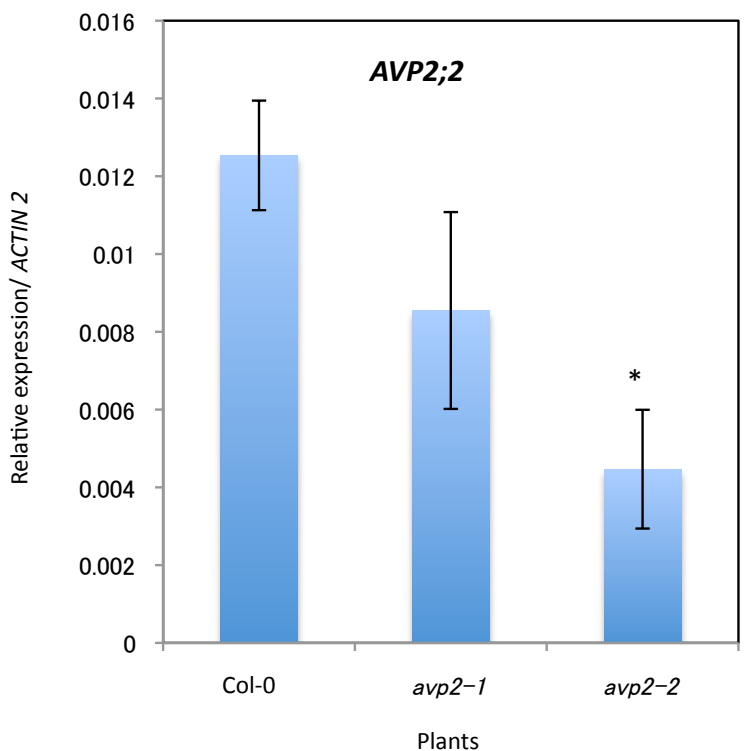

Fig. 2. The reduced expression of $A V P 2 ; 1$, and $A V P 2 ; 2$ in isolated type II H+-PPase-defective mutants. (A) $A V P 2 ; 1$ gene expression. (B) $A V P 2 ; 2$ gene expression. Each datum is the mean of three independent experiments, and represented as means $\pm \mathrm{SE}$. Asterisks indicate a value that significantly different from that of Co- 0 at $P<0.05$ using student's $t$-test. 


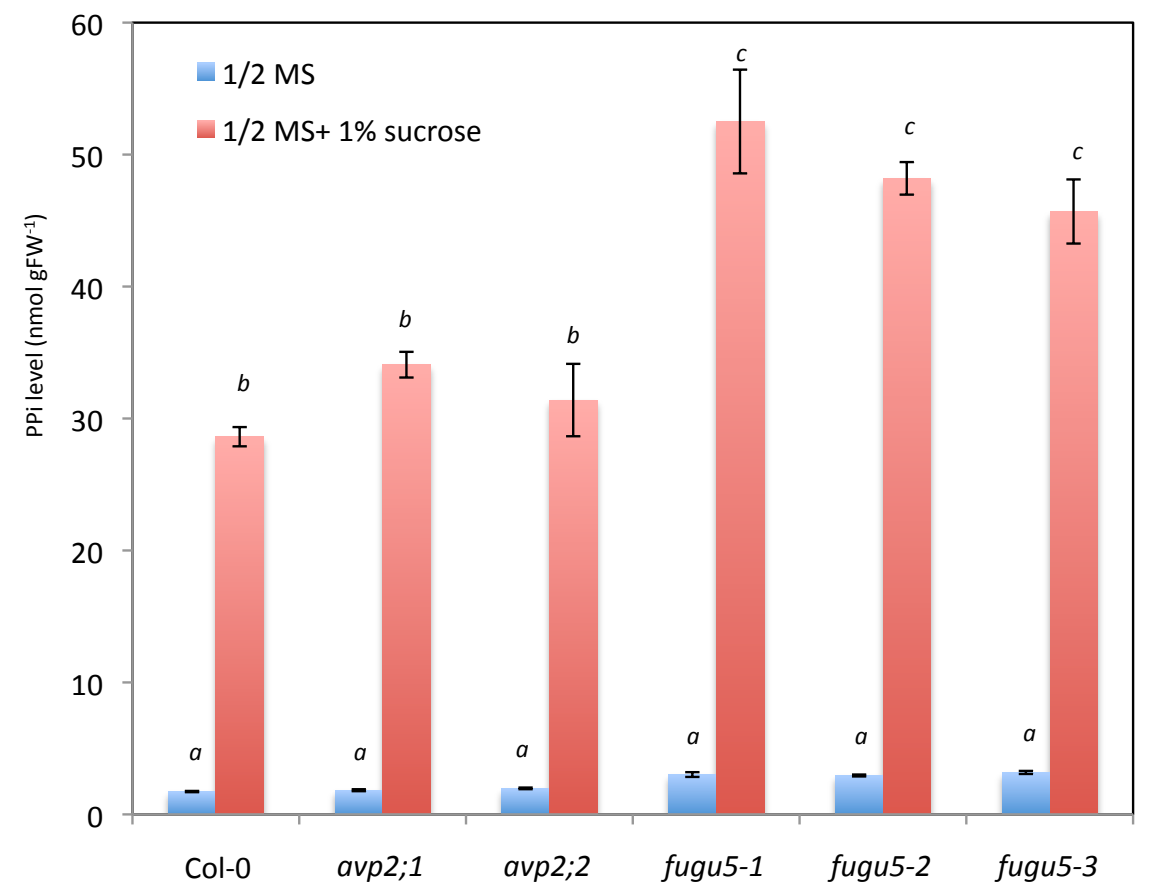

Fig. 3. PPi accumulation in fugu 5 mutants. Plants were grown for one week on sugar-free $1 / 2 \mathrm{MS}$ medium, or on $1 / 2$ MS supplemented with $1 \%$ sucrose. Data represent the mean \pm SE for three replicates. Different letters indicate statistically significant difference at $P<0.05$ by using Tukey's HSD method. 
(A)

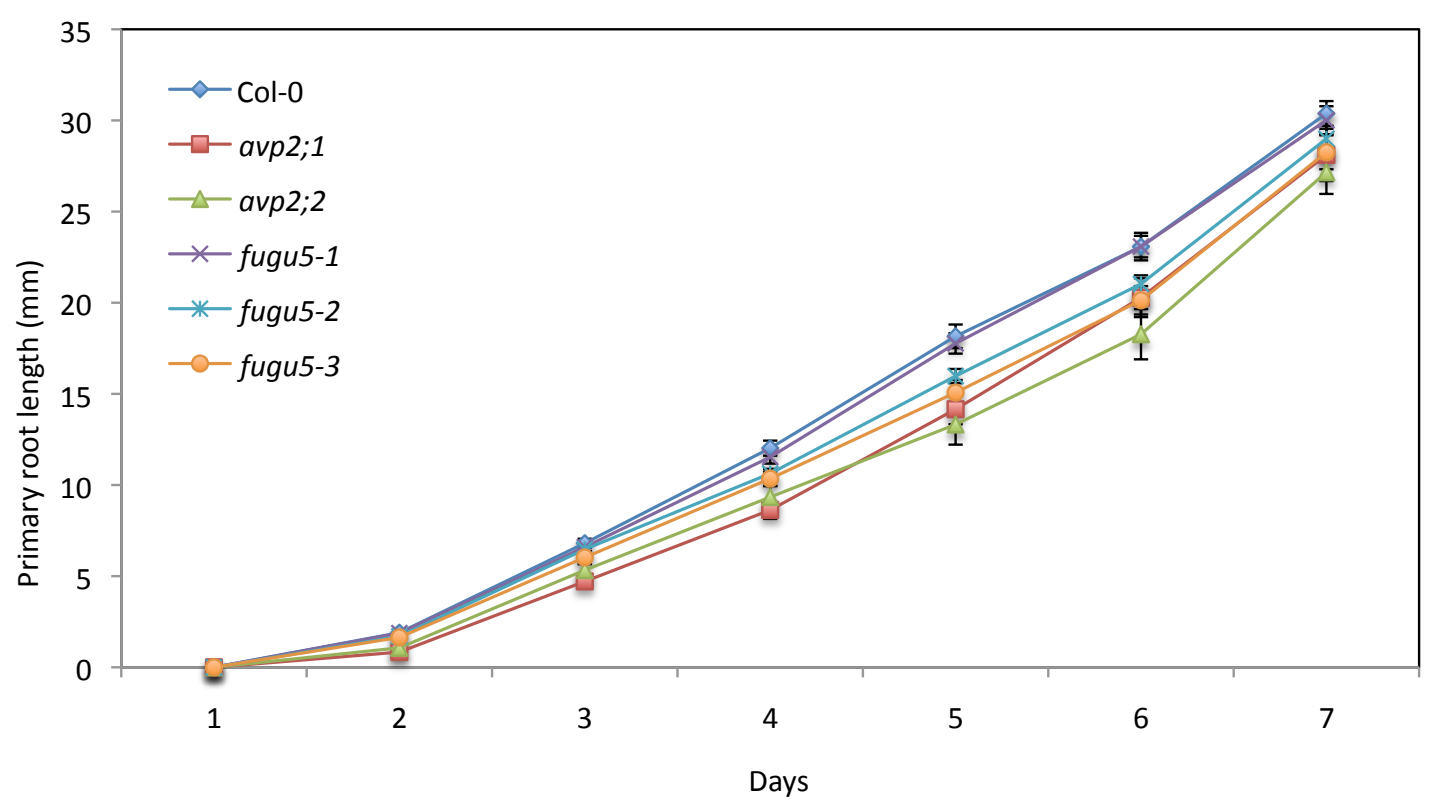

(B)

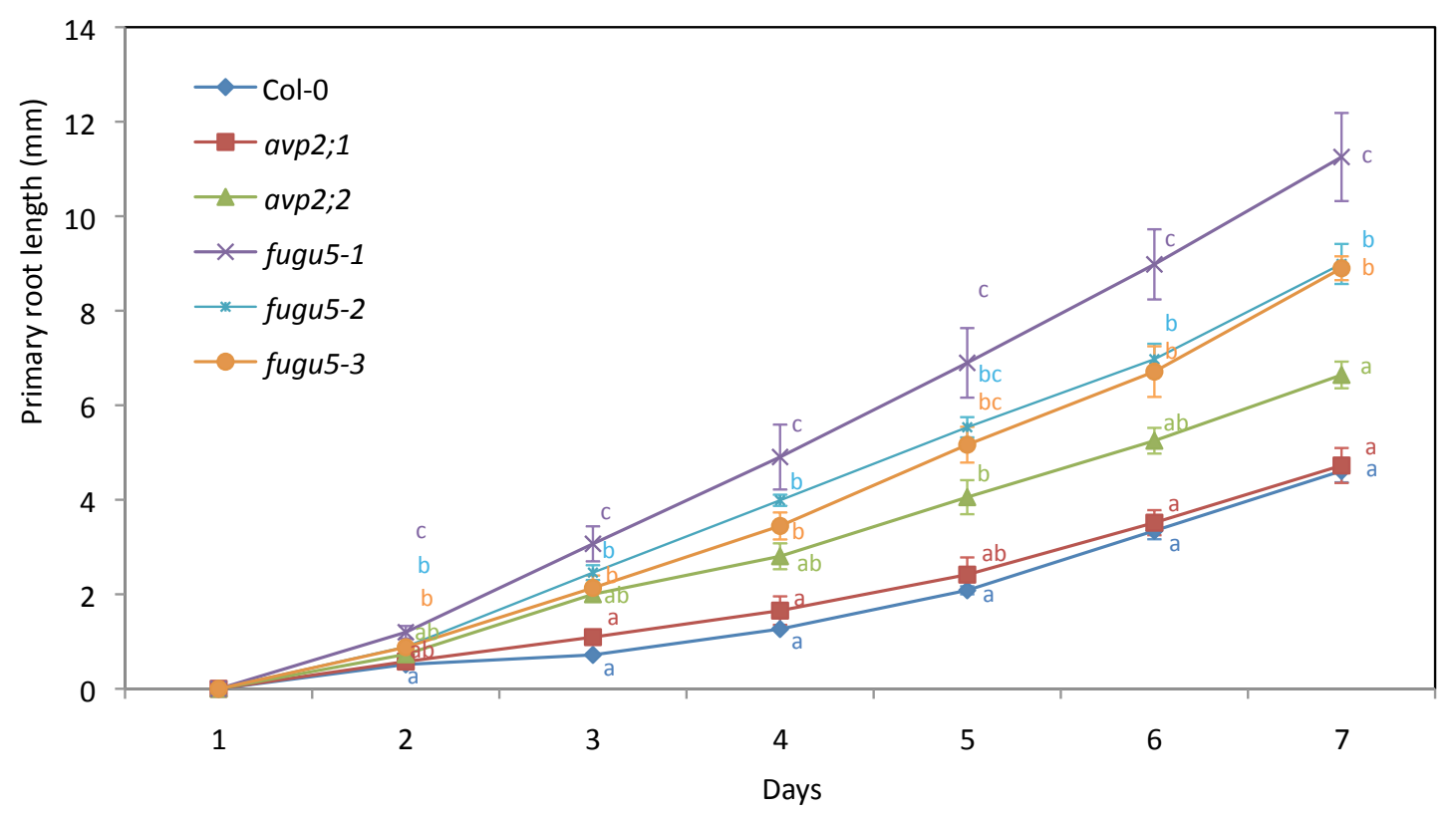

Fig. 4. Effect of sugar starvation on primary root growth of $\mathbf{H}^{+}$-PPase-defective mutants. Plants were grown on sugar-free $1 / 2$ MS medium (A), or on $1 / 2$ MS supplemented with $1 \%$ sucrose (B). The root growth was monitored daily, and the root length was measured using ImageJ software. All plants were grown under low light conditions. Data represent the mean \pm SE. $15 \leq n \leq 20$ for (A) and $30 \leq n \leq 60$ for (B). Different letters indicate statistically significant difference at $P<0.05$ by using Tukey's HSD method. 


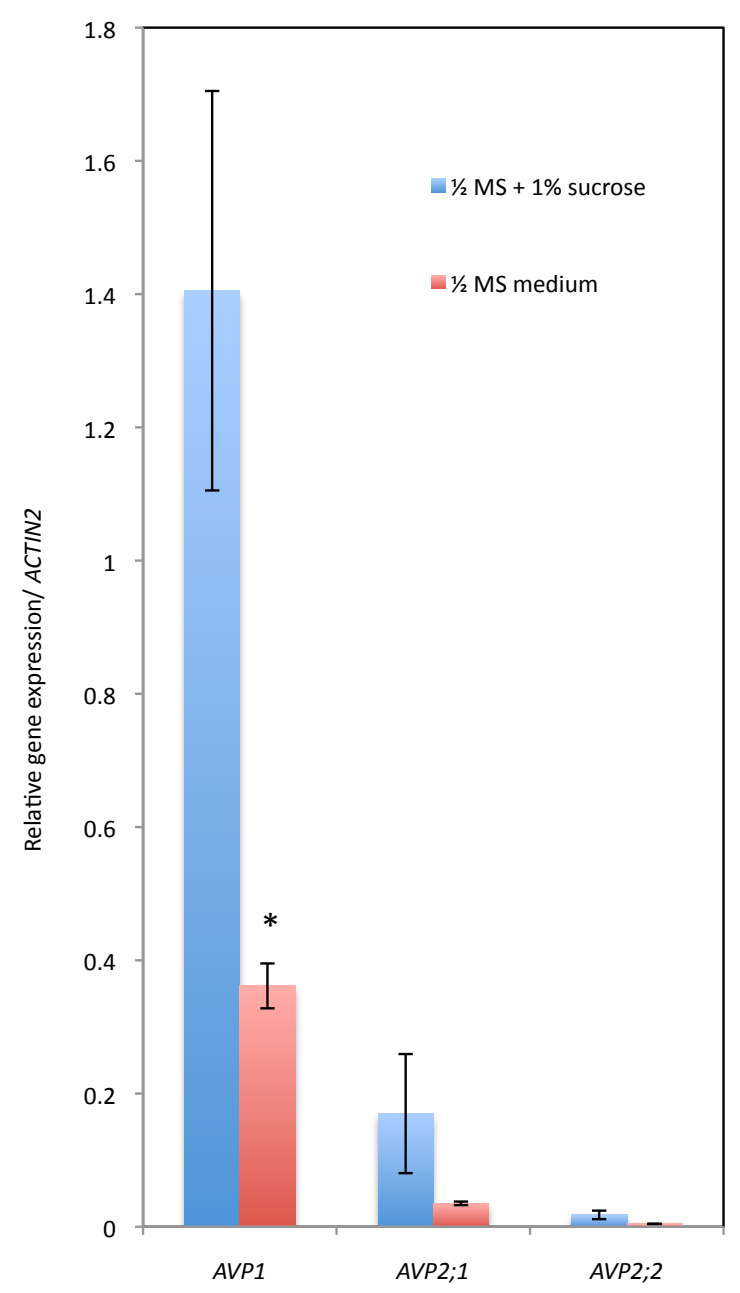

Fig. 6. Effect of sugar starvation on $\mathbf{H}^{+}$-PPase-encoding genes expressions. RNA was extracted from plants grown for one week on $1 / 2 \mathrm{MS}$ medium under low light condition. Data represent mean $\pm \mathrm{SE}$ of three replicates. Gene expression was normalized against ACTIN2 gene. Asterisk indicates a value that significantly different from that of Co- 0 at $P<0.05$ using student's $t$-test. 
(A)

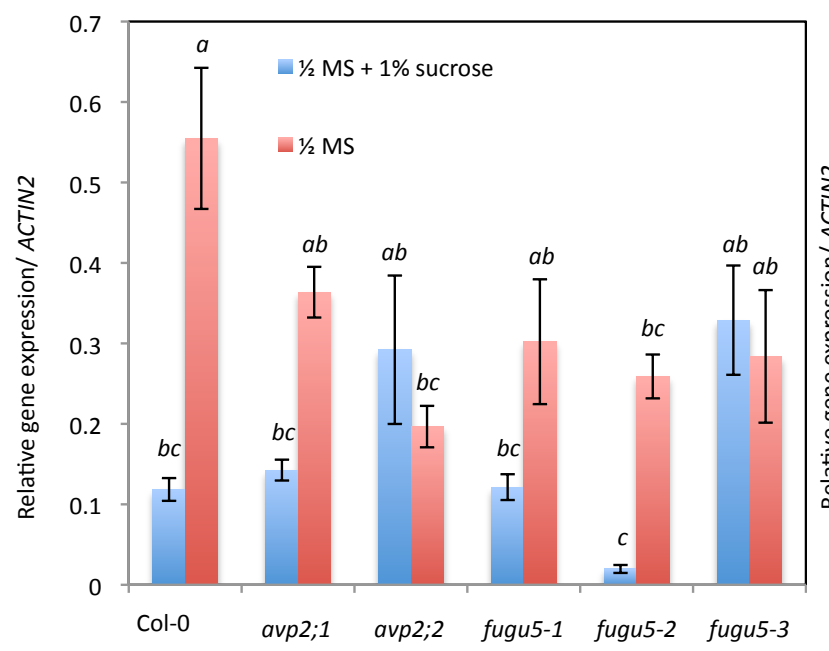

(B)

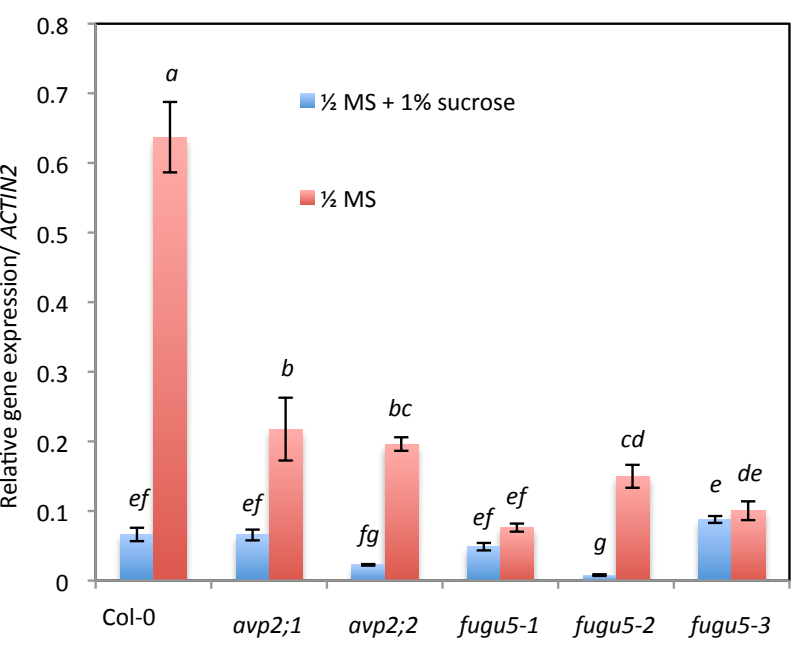

Fig. 7. Effect of sugar starvation on DIN1 and DIN6 gene expression of $\mathrm{H}^{+}$-PPase-defective mutants. (A) DIN1 gene expression. (B) DIN6 gene expression. RNA was extracted from plants grown for one week on $1 / 2 \mathrm{MS}$ medium under low light condition. Data represent mean $\pm \mathrm{SE}$ of three replicates. Gene expression was normalized against ACTIN2 gene. 


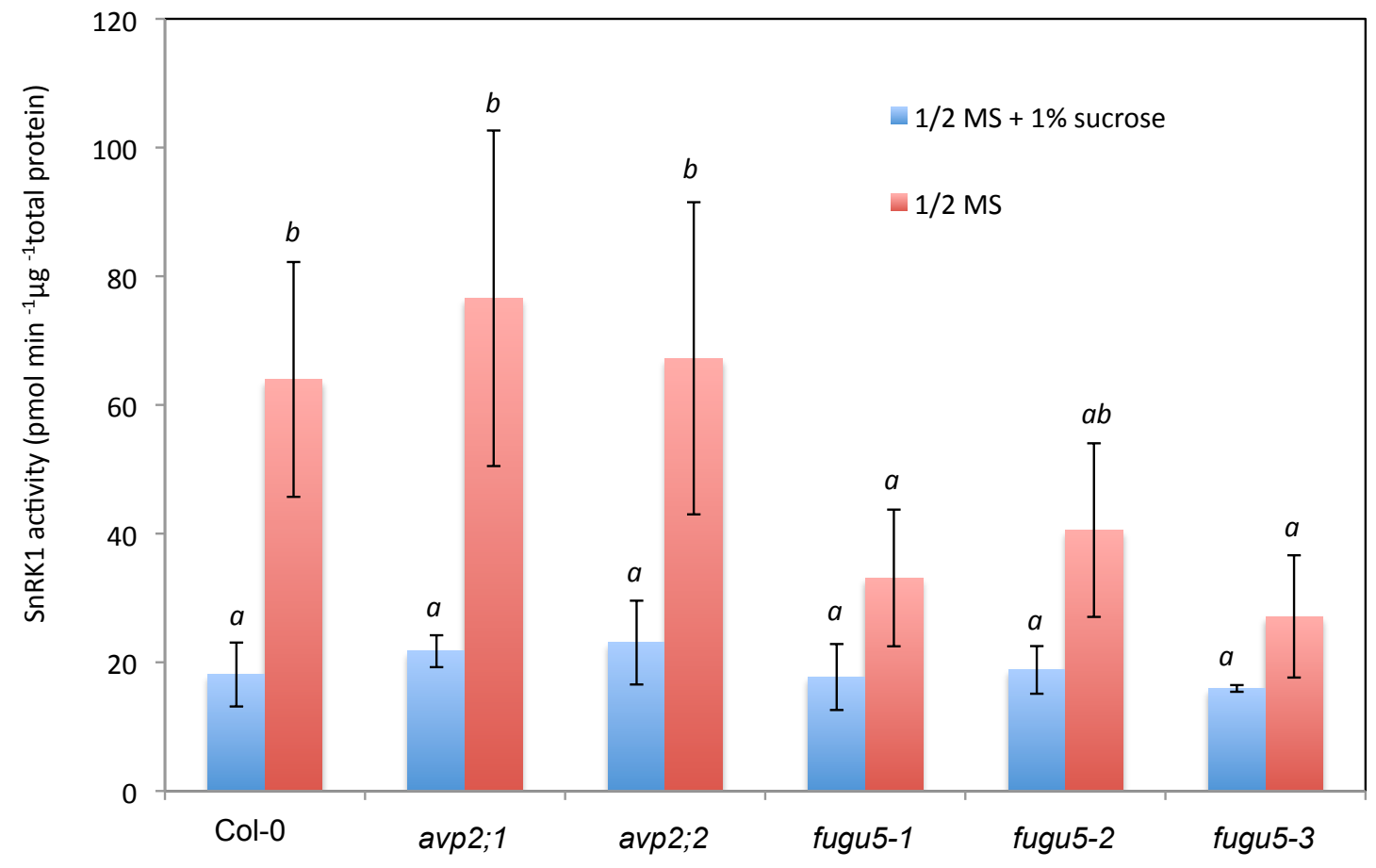

Fig. 8. Reduction of SnRK1 activity in $\mathbf{H}^{+}$-PPase defective-mutants. SnRK1 activity was measured by using a liquid scintillation counter after removing unincorporated $\left(\gamma^{-33} \mathrm{P}\right)$ ATP from reaction mixture. Total protein was extracted from plants grown for one week on $1 / 2$ MS medium under low light condition. Data represent mean \pm SE of three replicates. Different letters indicate statistically significant difference at $P<0.05$ by using Tukey's HSD method. 
(A)

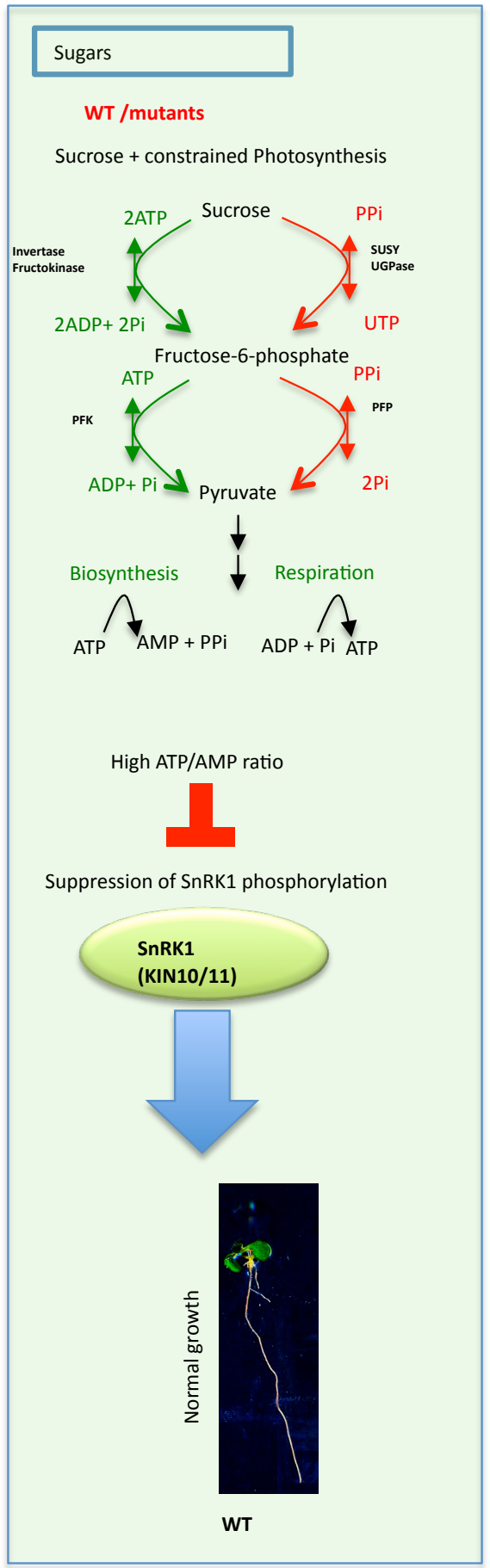

(B)

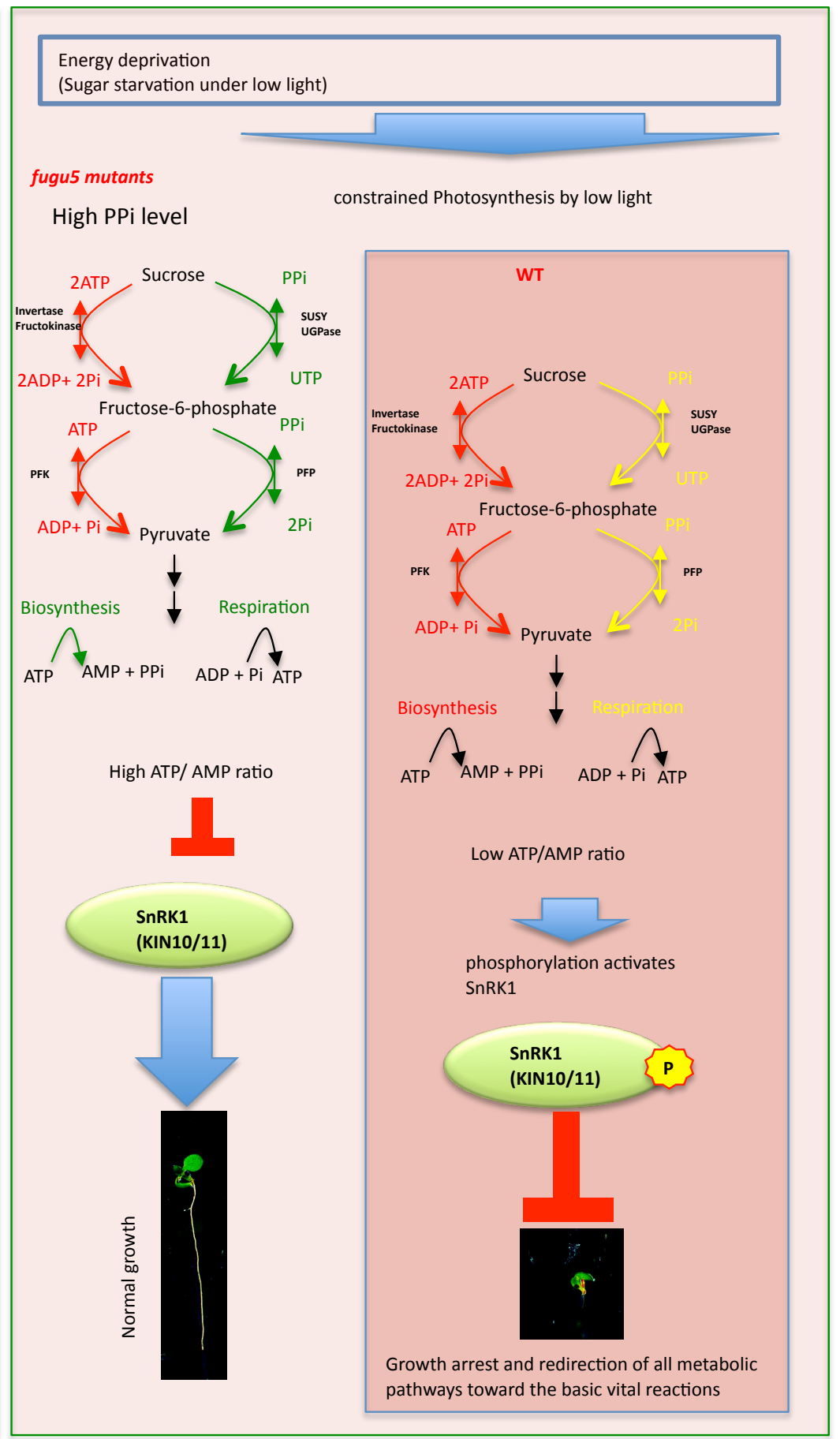

Fig. 9. A hypothetical model for PPi-mediated sugar starvation tolerance. Sucrose degradation by invertase followed by phosphorylation of resulted glucose and fructose by frucktokinase requires two molecules of ATP. Sucrose degradation by sucrose synthase (SUSY) followed by UGPase require only one molecule of PPi. Fructose-6-phosphate is phosphorylated by ATP-dependent phosphofructokinase (PFK), or PPi-dependent phosphofructokinase. (A) Sucrose in growth medium is sufficient to support the semi-heterotrophic growth under low light condition. The ATP dependent reactions have the advantage over the PPi dependent reactions. High ATP to AMP ratio inhibits Sucrose-non-fermenting related protein kinase 1 (SnRK1) activity, which controls gene expression and protein phosphorylation in a way that induces catabolism and inhibits anabolism. (B) The low light constrains photosynthesis, and the absence of sugar from the growth medium induces sugar starvation and arrests plant growth in wild-type plants. The low ATP/AMP ratio activates SnRK1 through phosphorylation. The high PPi level in $\mathrm{H}^{+}$-PPase-defective mutants facilitates PPi-dependent reactions and conserve ATP. The comparatively high ATP/AMP ratio inhibits SnRK1. 


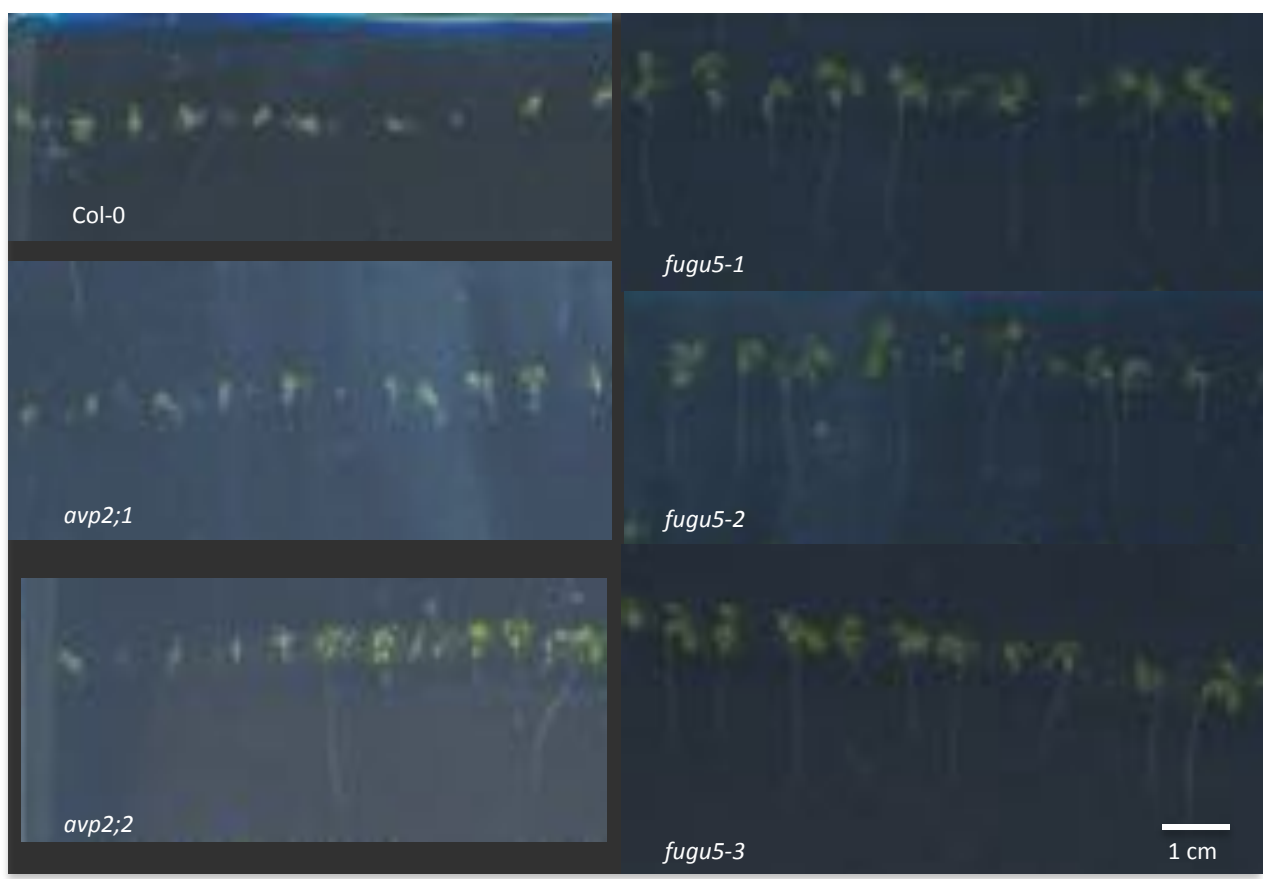

Fig. 5. Effect of sugar starvation on primary root growth of $\mathbf{H}^{+}$-PPase-defective mutants. Plants were grown for 7 days on sugar-free $1 / 2$ MS medium, under low light condition. 